'bait shyness' in rats and J. Rogers (US Fish and Wildlife Service) reported that it also works with birds. In laboratory trials, red-winged blackbirds would avoid eating a foodstuff for more than 16 weeks after first encountering it mixed with the insecticide methiocarb, and this conditioned aversion was effective even when the only alternative food was highly unpalatable. Large scale field trials showed that methiocarb can reduce bird damage to vineyards by something like fivefold.

I. Inglis (Pest Infestation Control Laboratory, Worplesdon) described the efficacy of different kinds of visual scaring devices. The traditional scarecrow, and popular modern equivalents consisting of bright coloured miniature windmills are totally ineffective, and Inglis suggested that a knowledge of the behaviour of pest species is useful in designing more effective birdscarers. For example, when a woodpigeon is frightened and takes to the air, it reveals conspicuous white wing patches which might be seen by other pigeons as a danger signal. This led Inglis to try out the deterrent effect of pairs of pigeon wings lying on the ground, and in one study birds were largely deterred from landing in a clover field for up to 70 days by the sight of pigeon wings on the ground. Similarly, Brent geese were discouraged from landing in a field by putting out model geese in an 'alert anxiety' posture. One of the most effective deterrents of all is the sight of a man flapping his arms up and down like a giant eagle, and there is now available on the market a 7-foot high Incredible Hulk with mechanical flapping arms. All these scaring devices suffer from the problem of habituation: birds eventually learn to stop flying away from them unless occasionally reminded with a gun that there is a real danger. It may turn out in the end, as suggested in one of the discussions. that the best solution to bird scaring is the one recommended in 1668 by Gervais Markham in Farewel to Husbandry: "The only best and safest means to prevent this evil is to have eversome young boys with bows and arrows to follow the seedman and harrows, making a great noise and shooting his arrows where he shall see these devourers aleight, not ceasing but chasing them from the land".

The meeting also touched on a more fundamental ecological issue raised by all techniques of scaring, deterring, or luring away bird pests: what happens to birds when they are frightened off a particular field? If they go next door, the problem is merely shifted on to someone else. One possibility, discussed by M. Owen (Wildfowl Trust, Slimbridge) is to provide refuges for birds,

\title{
The leaning tower
}

\section{from Ian Smalley}

Because the Tower of Pisa was built very slowly, with many interruptions, it still stands; had it been completed during the 12th century it would probably have collapsed (Mitchell, Vivatrat \& Lambe J. Geotech. Eng. Div. Amer. Soc. Civ. Eng. 103, 227; 1977). Work on the foundations of the tower began in August, 1173 and the first story was completed in 1174. When the tower reached a height of three and a half storeys and a load of 9,840 metric tons in 1178 the work stopped. The work stoppage has been attributed to politics, to the heavy work load of the constructors, and to construction difficulties. Construction was not resumed until almost a century later and then the tower was completed up to the eight storey level, and to a total load of $13,728 \mathrm{t}$, during the period 1272-1278. Work then stopped again and did not resume until 1360 when the final storey was added and the whole tower completed in 1370. By the time of the final stage of construction the lean of the tower was significant and the centre line of the topmost part was changed on account of this.

Mitchell et al. concluded that the bcaring capacity of the soils underlying the tower was never exceeded. The total settlement of the tower is due to the sum of four components: an immediate compression of the sands in a $7 \mathrm{~m}$ thick zone underlying the base of the tower, immediate compression of a $30 \mathrm{~m}$ thick clay layer underlying the sands, consolidation of the clay layer and secondary compression of the clay layer. They were unable to show, using their classical soil mechanics methods, why the tower actually leans although they suggested that this might be due to the higher compressibility of the foundation sand on the south side of the tower. Veder (Bauingenieur 50, 204; 1975) had suggested earlier that the stone blocks used in the construction were stored on the south side of the tower causing an asymmetric loading.

Although the tower leans to the south now, it seems to have pointed

and an alternative is the one mentioned earlier in the context of bullfinches, to provide a different food supply. These courses of action may. however, exacerbate the problem. If a

John Krebs is a Lecturer in Zoology at the Edward Grey Institute of Field Ornithology University of Oxford. in various directions during its construction. From 1173 to 1178 twothirds (in terms of weight) of the tower was constructed and it tilted towards the north-east. By the time construction resumed in 1272 this inclination had doubled. Inclination increased for a further 6 years at which time $86 \%$ of the final weight was in place. The tower then leant towards the north-west, and in 1370 when the tower was completed its inclination was towards the south, as it is today. The tilt was $1 / 31$ in 1370 but today it is around $1 / 10$ and, after a deceleration of movement for five and a half centuries, movements are today tending to accelerate. Much of the recent movement can be related to the removal of water from nearby wells and the lowering of the piezometric head in the deep sandy layer (Mascardi J. Geotech. Eng. Div. Amer. Soc. Civ. Eng. 104, 299; 1978).

Cambefort (J. Geotech. Eng. Div. Amer. Soc. Civ. Eng. 104, 156; 1978) has calculated that the tower will be stable until the year 2780 , as long as the pumping from the deep aquifer does not increase beyond the 1966 rate. $\mathrm{He}$ has also proposed an ingenious lever mechanism to halt the tilt and fix the tower in its present position; a lever arm extending 12.3 $\mathrm{m}$ from the tower centre and a load of $600 \mathrm{t}$ would apparently provide the necessary counterforce. Alternative solutions to the engineering problem are however still being sought; and there is still no consensus on what actually caused the tilt. Perhaps the most ingenious theory is still that advanced by Kerisel (Geotechnique 25,$433 ;$ 1975) who invoked the Coriolis force due to the roation of the Earth. Is it possible, wondered Kerisel, that a structure with a very low safety factor might be influenced by sustained small forces acting over several centuries?

Ian Smalley is with the Soil Engineering Section, DSIR Soil Bureau, Lower Hutt, New Zealand.

pest species survives better as a result of the provision of refuges or alternative food supplies, it may return in great numbers in future years to attack agricultural crops. This kind of problem cannot be resolved without more knowledge of the factors determining survival and movements of bird pests. 